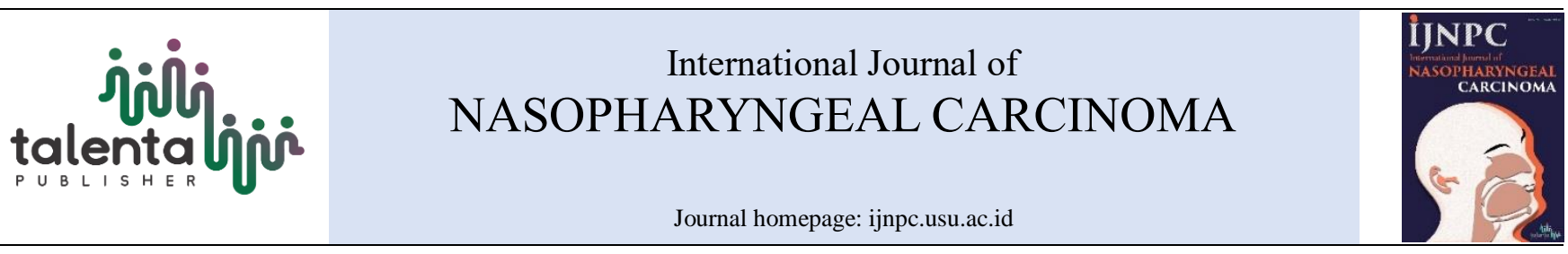

\title{
EFFECT OF SEA CUCUMBER OIL AND HONEY IN POST RADIOTHERAPY NASOPHARYNGEAL CARCINOMA PATIENTS
}

\author{
Wawan Hendrawan, Bogi Soeseno, Tonny Basriyadi S, Yussy Afriani D, Ade Burhanudin* \\ Department of Otorhinolaryngology-Head and Neck Surgery, Faculty of Medicine Padjadjaran University/Hasan Sadikin General Hospital, \\ Bandung, Indonesia
}

\begin{abstract}
Introduction: Nasopharyngeal carcinoma is one of the most commonly found cases of head and neck malignancy. The most common side effects of radiotherapy is skin damaged. Until now, there is no standard therapy that has been given to post radiotherapy patient in Hasan Sadikin Hospital. Sea cucumber and honey can accelerate the healing process of the wound caused by radiotherapy.

Objective: This study was conducted to compare the effects of the use topical sea cucumber oil and honey in patient with nasopharyngeal carcinoma post radiotherapy.

Method: The study was conducted at Radiotherapy Clinic in Hasan Sadikin Hospital from may until September 2015 with patients who experienced skin damaged level two or more based on the criteria of Radiation Therapy Oncology Group (RTOG). This was an experimental study. Subjects were selected consecutively between the two groups: sea cucumber oil group and honey group. The draft analysis was done using Randomized Controlled Trial (RCT).

Result: 30 patients were divided equally into two groups, sea cucumber group and honey group. Most of the nasopharyngeal carcinoma patients were $>45$ years old, the ratio man to woman was $2-3: 1$, with the BMI was <18.5. All subjects in this study experienced recovery rate up to level $1(\mathrm{p}=1.0)$, after one week of treatment. In the 2nd week after treatment all patients in the sea cucumber group achieved recovery up to level 0 , and in the honey group as much as 2 patients only experienced the recovery rate to level 0 , while the remaining 13 subjects remained at level $1(\mathrm{p}=0.0001)$. It was found that the wound healing process occurs better in sea cucumber oil group than the honey group $(\mathrm{p}=0.0001)$.

Conclusion: Sea cucumber oil accelerates the healing process of the skin tissue damaged in patients with nasopharyngeal carcinoma after radiotherapy, faster than with honey.
\end{abstract}

\section{Article Info}

Keywords:

Nasopharyngeal carcinoma, skin damaged, honey, sea cucumber oil, radiotherapy

\section{*Corresponding author}

Address: Jl. Raya Bandung Sumedang No.KM 21, Hegarmanah, Kec. Jatinangor, Kabupaten Sumedang, Jawa Barat 45363

e-mail: burhanudin.ade@gmail.com

\section{INTRODUCTION}

NPC is a frequent cancer in Indonesia, rating as the fourth most common tumor after cervical cancer, breast cancer, and skin cancer, and is the most common malignancy in the head and neck. NPC incidence estimated at $6.2 / 100,000$ or about 12,000 new cases per year [1]. Prevalence of Nasopharyngeal Carcinoma in the Ear Nose Throat Head and Neck Surgery (ENT-HS) Department Dr. Hasan Sadikin Hospital (RSHS) Bandung is $43.7 \%$ in $2010-2014$ which ranks first in the ENT-HS Department [2].

The main therapy for NPC is radiotherapy for early stages, chemotherapy or combination for advanced stages. Radiotherapy is the main treatment for the classification of $\mathrm{T} 1$ and $\mathrm{T} 2$ as much as $75-90 \%$ of cases, $\mathrm{T} 3$ and T4 as much as $50-75 \%$ of cases. Radiotherapy is also used for lymph node metastasis (KGB) in $\mathrm{N} 0$ and $\mathrm{N} 1$ as much as $90 \%$ but this number decreases to $70 \%$ in cases N2 and N3 [3].

Skin damage reactions are one of the most common complications experienced by patients who get radiotherapy. Skin damage ranging from mild reddish spots to severe ulceration. Approximately $85 \%$ of patients who get radiotherapy will experience moderate to severe skin damage, cause itching and pain [4]. The condition of skin damage due to radiotherapy based on RTOG criteria is grouped into: Level 0 (no visible changes in sight), Level 1 (faded red erythema), Level 2a (bright red erythema with or without dry desquamation), partial loss of cells basal epidermis, dry, itchy, noisy, flaky, flaking, and hyperpigmented. Level $2 \mathrm{~b}$ (partial wet desquamation, moderate edema), Level 3 (overall desquamation, pitting edema), total damage to the basal cell layer, blisters or vesicles formed, exposure of nerves and pain, and serous secretion [5].

Wound care is an action that must be taken in patients after radiotherapy. The main purpose of wound care is to restore skin integrity and prevent infection complications. Wound care includes topical antibacterial administration, wound dressing and dressing replacement [6]. Today the trend of treatment with herbs is in great demand and as an alternative destination for medical treatment. In developed and developing countries many studies have been conducted to prove the efficacy of herbs scientifically. An herbal example released by Complementary Alternative Medicine (CAM) is sea cucumber oil and honey. Indonesia is a country rich in various kinds of herbal medicines and abundant natural production. At present the two herbs are easily available and available at herbal outlets [6].

The use of sea cucumber oil as a traditional antiseptic and multipurpose drug has been known for 300 years ago [7]. Zohdi et al. (2011) reported a significant wound contraction rates for $\mathrm{S}$. hermanii-based hydrogel wound dressing at day 21 and 28 post burn wound. This may indicate that the novel cross-linked sea cucumber hydrogel (S. hermanii) dressings act at later stage of wound healing phase, which might be associated with reservoir capacities of hydrogel for the delivery of sea cucumber on the wounded skin [8]. In contrast, Subramaniam et al. (2013) showed that topical application of S. horrens exhibited significantly smaller wounds at day $4(\mathrm{p}<0.001)$, but no significant change on days $8,12,16$ and 21 when compared to negative control $(p>0.05)$. This indicated that direct topical application of sea cucumber may enhance wound contraction at the initial period of wound healing [9].

As for antibacterial property of sea cucumber, Mariana et al. (2011) concluded that sea cucumber crude extract has potential to become an alternative resource for anti-MRSA drugs [10]. Apart from that, sea cucumber also possesses antioxidant property that can scavenge free radicals, whereby the presence of excessive free radicals is associated with impaired wound healing. The antioxidant activity of sea cucumber species; Bohadschia mamorata vitiensis, S. variegatus Semper, and S. badionotus Selenka might be contributed by the content of coelomic fluid, as reported by Hawa et al. (1999) [11]. 
Sea cucumbers contain fatty acids including arachidonic acid (AA C20: 4), eicosapentaenoic acid (EPA C20: 5), and docosahexaenoic acid (DHA C22: 6) which has a potential role in tissue repair and wound healing [12]. Sea cucumbers contain anticoagulants and antithromboses, anti-cholesterol and substances that can reduce fat levels, anticancer, and antibacterial by inhibiting the growth of E. Coli, K. pneumoniae, P. aeruginosa, S. Aureus, etc [13-16].

Honey contain a mixture of sugar, enzymes, amino acids, vitamins, minerals, organic acids, carbohydrates, and aromatics with varied compositions. Honey has broad-spectrum antibiotics that can eradicate bacteria from wounds, and contain components that can suppress free radicals and work as anti-inflammatory. Honey can overcome rapid type damage to skin tissue exposed to radiation [4, 17-19]. Honey can improve the process of granulation and epithelialization of tissue during the proliferation phase, and reduce the time needed for wound healing [19-21]. Sea cucumber oil and honey are very practical, easy to give, and easy to obtain. Sea cucumber oil has a cheaper price than topical honey. Skin damage that occurs post-radiotherapy in NPC patients causes negative effects and decreases in quality of life. Failure to deal with post-radiotherapy side effects causes a reduction in patient obedience to treatment. It is very important for post-radiotherapy sufferers to do skin care to reduce the side effects that occur. On the basis of the above background, the researcher was interested in comparing the administration of sea cucumbers oil and honey to the repair of neck skin damage in NPC patients post-radiotherapy.

\section{MATERIAL AND METHODS}

This study was approved by the ethics committee of the Dr. Hasan Sadikin Hospital (RSHS) Bandung. This research was performed according to the principles of the Declaration of Helsinki. Informed consent was obtained from the patients and their family members.

This research is an experimental study, given the treatment on the subject of research, then the effect of treatment measured and analyzed. The inclusion criteria of the study subjects were NPC patients post-radiotherapy who had second grade or more skin damage based on the RTOG scale. The exclusion criteria for this study had a history of undergoing radiotherapy, chemotherapy or combination. Residual or recurrent NPC, NPC with multiple carcinoma, NPC with distant metastasis and have diabetes mellitus.

Research subjects were consecutively selected for NPC subjects postradiotherapy at the clinic of radiotherapy Dr. Hasan Sadikin Hospital Bandung which is in accordance with the inclusion criteria. Divided into 2 treatment groups: topical sea cucumber oil and topical honey group. Gauze containing the sea cucumber oil or topical honey is placed on the wound in the neck, then covered with wet gauze, performed twice a day and washing the neck with warm water before replacing the gauze. Evaluation of wound degree based on RTOG and wound area before and after treatment and compared the duration of healing between the two treatment groups. Evaluation is carried out every week for 1 month. However, if the degree of injury has reached 0 degrees based on the RTOG, then the subject is declared cured and not evaluated the following week. Other variables assessed were the subject's previous skin condition, age, surgical history, and nutritional status.

A statistical test to compare two-group numerical data with the unpaired $\mathrm{T}$ test when the data is normal distribution, and the Mann Whitney test when the data is not under normal distribution. After the homogeneous test, then test the normality of data with Shapiro Wilks. Fisher Exact test were used for comparisons clinical condition of skin and length of healing in both group and unpaired $\mathrm{T}$ test used to comparisons of wound area in both treatment groups. The level of significance was set at $\mathrm{p}<0.05$.

\section{RESULT}

The study was conducted at the Radiotherapy Department of the Dr. Hasan Sadikin Hospital Bandung, during the period of May-September 2015 obtained as many as 32 research subjects, but there were 2 people who did not follow until the end of the study period. One person because of the disobedience of the subject in using sea cucumber oil, while one person is again because of the distance to a far hospital so that he cannot control regularly to the hospital. The research subjects were divided into 15 sea cucumber oil groups and 15 honey groups. The general characteristics of the research subjects included gender, age, and BMI. The description of the characteristics of the research subject can be seen in table 1 .
Table 1. Characteristics of Subjects in Both Treatment Groups

\begin{tabular}{|c|c|c|c|c|}
\hline & \multirow[b]{2}{*}{ Characteristics } & \multicolumn{2}{|c|}{ Groups } & \multirow[b]{2}{*}{ P Value } \\
\hline & & $\begin{array}{c}\text { Sea cucumber oil } \\
(n=15)\end{array}$ & $\begin{array}{l}\text { Honey } \\
(\mathrm{n}=15)\end{array}$ & \\
\hline \multirow[t]{3}{*}{1} & Gender & & & \\
\hline & Male & $11(73.30 \%)$ & $11(73.30 \%)$ & $1.000 *$ \\
\hline & Female & $4(26.70 \%)$ & $4(26.70 \%)$ & \\
\hline \multirow[t]{12}{*}{2} & Age (year) & & & \\
\hline & $5-11$ & $0(0 \%)$ & $0(0 \%)$ & \\
\hline & $12-16$ & $2(13.3 \%)$ & $0(0 \%)$ & \\
\hline & $13-25$ & $0(0 \%)$ & $0(0 \%)$ & \\
\hline & $26-35$ & $1(6.7 \%)$ & $0(0 \%)$ & \\
\hline & $36-45$ & $2(13.3 \%)$ & $3(20 \%)$ & \\
\hline & $46-55$ & $7(46.7 \%)$ & $8(53.3 \%)$ & \\
\hline & -65 & $3(20 \%)$ & $4(26.7 \%)$ & \\
\hline & $>65$ & $0(0 \%)$ & $0(0 \%)$ & \\
\hline & Mean \pm SD & $44.13 \pm 13.60$ & $49.53 \pm 7.36$ & $0.389 * *$ \\
\hline & Median & 47 & 48 & \\
\hline & Range & $15-60$ & $37-60$ & \\
\hline \multirow[t]{4}{*}{3} & BMI & & & \\
\hline & Mean \pm SD & $17.21 \pm 0.51$ & $17.10 \pm 0.55$ & $0.624 * *$ \\
\hline & Median & 17.2 & 17.03 & \\
\hline & Range & $16.41-17.78$ & $16.08-17.78$ & \\
\hline
\end{tabular}

Information:

*: Fisher Exact test

From table 1, it was found that men were more than women with a ratio of 2.75: 1 in both groups. Obtained a value of $p=1.0$, which means there is no significant difference between the two groups, which means the subjects in both groups can be considered homogeneous. The mean of the sea cucumber oil group was $44.2 \pm 13.60$ with a range of $15-60$ years, whereas in the honey group the mean age was 49.6 \pm 7.4 with a range of 37-60 years. The age of most nasopharyngeal carcinoma subjects in this study was age $>45$ years. The $p$ value for the patient age variable and BMI is 0.389 and 0.624 . Both of these variables have a value of $p>0.05$, which means there are no significant differences between the two groups. Based on the characteristics analysis above because all values of $\mathrm{p}>0.05$, it can be said that the two research groups are considered homogeneous.

Evaluation of wound degree was done based on RTOG before and after treatment and compared between the two treatment groups. Evaluation is carried out every week for one month, if the degree of injury has reached 0 degrees based on RTOG, the subject is declared cured and no evaluation is carried out the following week. To find out the comparison of clinical conditions of skin based on RTOG criteria, the table is presented as follows:

Table 2. Comparison of Clinical Conditions of Skin Based on RTOG Criteria

\begin{tabular}{|c|c|c|c|c|}
\hline \multirow[b]{2}{*}{ Time } & \multirow[b]{2}{*}{ RTOG } & \multicolumn{2}{|c|}{ Group } & \multirow[b]{2}{*}{ P Value* } \\
\hline & & $\begin{array}{c}\text { Sea Cucumber oil } \\
(n=15)\end{array}$ & $\begin{array}{l}\text { Madu } \\
(n=15)\end{array}$ & \\
\hline \multirow[t]{2}{*}{0 week } & $2 a$ & $15(100 \%)$ & $15(100 \%)$ & 1,000 \\
\hline & $2 \mathrm{~b}$ & $0(0 \%)$ & $0(0 \%)$ & \\
\hline \multirow[t]{3}{*}{1 week } & 1 & $15(100 \%)$ & $15(100 \%)$ & 1,000 \\
\hline & $2 \mathrm{a}$ & $0(0 \%)$ & $0(0 \%)$ & \\
\hline & $2 \mathrm{~b}$ & $0(0 \%)$ & $0(0 \%)$ & \\
\hline \multirow[t]{2}{*}{2 week } & 0 & $15(100 \%)$ & $2(13.3 \%)$ & 0.0001 \\
\hline & 1 & $0(0 \%)$ & $13(86.7 \%)$ & \\
\hline \multirow[t]{2}{*}{3 week } & 0 & $0(0 \%)$ & $15(100 \%)$ & 1,000 \\
\hline & 1 & $0(0 \%)$ & $0(0 \%)$ & \\
\hline
\end{tabular}

Information:

* Fisher Exact test

In table 2, one week after the treatment it was seen that all groups of sea cucumber oil and honey had improved to level 1. Skin conditions in both groups of week 0 and first week with $\mathrm{p}$ values were obtained for 1,000 , this indicates that in the first week there were no differences RTOG in both groups. All subjects in the sea cucumber oil group (100\%) improved to level 0 at week 2 , while the honey group only 2 subjects $(13.3 \%)$ who recovered to level 0 and the remaining 13 patients $(86.7 \%)$ remained at level 1 . With the Exact Fisher statistical test, the $\mathrm{p}$ value for the clinical condition of the patient's skin was obtained based on the RTOG criteria of 0.0001 , which meant that it was very different statistically significant. At the third week, it appears that all subjects from the two honey groups experienced improvements to level 0 based on the RTOG.

To find out the comparison of wound area between sea cucumber oil and honey administration, the calculation is carried out as on table 3 , the mean wound area of week 0 (initial study) in the sea cucumber oil group $140.20 \pm 36.72$ and in the honey group was $155.27 \pm 31.08$ with a pvalue of 0.235 , thus it could be said that there was no difference in mean statistically significant between wound area at week 0 in both study groups. The results of the statistical test on the first and second week wound area in the two study 
groups above were obtained pvalue for the wound area in the first and second weeks was 0,0001 which means that there were differences in mean wound area in the first and second weeks which were very significant in both groups.

Table 3. Comparison of Wound Area in Both Treatment Groups

\begin{tabular}{|c|c|c|c|}
\hline \multirow[b]{2}{*}{ Time } & \multicolumn{2}{|c|}{ Wound Area $\left(\mathrm{cm}^{3}\right)$} & \multirow[b]{2}{*}{ P Value* } \\
\hline & $\begin{array}{c}\text { Sea Cucumber Oil } \\
(n=15)\end{array}$ & $\begin{array}{l}\text { Honey } \\
(\mathrm{n}=15)\end{array}$ & \\
\hline \multicolumn{4}{|l|}{ Week 0} \\
\hline Mean \pm SD & $140.20 \pm 36.72$ & $155.27 \pm 31.08$ & 0.235 \\
\hline Median & 144.00 & 156.00 & \\
\hline Range (min-max) & $80.00-244.00$ & $90.00-195.00$ & \\
\hline \multicolumn{4}{|l|}{ Week 1} \\
\hline Mean \pm SD & $1 \pm 0$ & $10.20 \pm 8.10$ & 0.0001 \\
\hline Median & 1 & 8 & \\
\hline Range (min-max) & $(1-1)$ & $(1-24)$ & \\
\hline \multicolumn{4}{|l|}{ Week 2} \\
\hline Mean \pm SD & $0 \pm 0$ & $0.87 \pm 0.35$ & 0.0001 \\
\hline Median & 0 & 1 & \\
\hline Range (min-max) & $(0-0)$ & $(0-1)$ & \\
\hline \multicolumn{4}{|l|}{ Week 3} \\
\hline Mean \pm SD & $0 \pm 0$ & $0 \pm 0$ & 1,000 \\
\hline Median & 0 & 0 & \\
\hline Range (min-max) & $(0-0)$ & $(0-0)$ & \\
\hline
\end{tabular}

Information:

*: P value was assessed by unpaired $\mathrm{T}$ test

To find out the duration of healing between administration of sea cucumber oil and honey, a time comparison is carried out as follows:

Table 4. Comparison of Length of Healing in Both Treatment Groups

\begin{tabular}{|c|c|c|c|}
\hline \multirow[b]{2}{*}{ Length of Healing } & \multicolumn{2}{|c|}{ Group } & \multirow[b]{2}{*}{ P Value* } \\
\hline & $\begin{array}{c}\text { Sea Cucumber oil } \\
(n=15)\end{array}$ & $\begin{array}{l}\text { Honey } \\
(\mathrm{n}=15)\end{array}$ & \\
\hline 1 week & $0(0 \%)$ & $0(0 \%)$ & \\
\hline 2 week & $15(100 \%)$ & $2(13.30 \%)$ & $<0.001$ \\
\hline 3 week & - & $13(86.70 \%)$ & \\
\hline
\end{tabular}

*: Fisher Exact test

From table 4, based on the duration of healing, it was found that in the first week there were no cured subjects in either group. Two weeks after therapy, all subjects in the sea cucumber oil group were cured while in the honey group only 2 subjects $(13.30 \%)$ were cured. The results of the statistical test obtained a $\mathrm{p}$ value of 0.0001 , which means that the duration of healing was very statistically significant in the two study groups. Sea cucumber oil therapy gave a faster healing time which was statistically significant compared to the honey group.

\section{DISCUSSION}

In table 1 , it was found that the age of most nasopharyngeal carcinoma subjects in this study was at the age of 46-55 years. Marlinda Adham et al, in Jakarta reported the characteristics of the subject of nasopharyngeal carcinoma in Dr. Cipto Mangunkusumo Hospital in the period 1995-2005, that the incidence of NPC was more at the age of 41-50 years. While the research of Madani et al, at Dr. Hasan Sadikin Bandung Hospital during 2010-2014 the most age group regarding the age group of 40-59 years, and the study conducted by Cao et al, in China reported the highest prevalence of NPC at the age of 40-59 years. All of these studies show a relatively mature age range, this is possible because the first exposure to carcinogenic material until the onset of cancer requires a long time so that the manifestation of nasopharyngeal carcinoma occurs in the relatively mature age $[1,2,22]$. Table 1 , shows that men are more than women with a $2.75: 1$ ratio in both groups. The same results were reported by the El-Sherbieny et al. Study, the ratio of NPC men and women 2-3: 1.9, whereas according to the study of Liu et al, there were more men than women namely 5.25:1.41 and Xiao et al. ratio of men to women 2.5:1.53 This condition is likely due to differences in lifestyle of men and women, such as smoking habits the number of smokers in men is more than women. Table 1, found that all subjects from both groups had BMI $<18.5$. This is probably due to radiotherapy causing side effects in the form of damage to the cells in the digestive tract, this damage causes loss of appetite, impaired soy sauce taste, pain swallowing, dry mouth, stomatitis, and narrowing of the esophagus.

These causes the food intake to decrease and the subject experiences low malnutrition and BMI [23]. In table 2, the clinical condition of the skin based on the RTOG criteria found that improvement in the clinical condition of the skin was significantly better than honey. In table 3, it was seen one week after the treatment, based on the area of injury, healing in the sea cucumber oil group was significantly better compared to the honey group, while in table 4, based on the duration of healing, sea cucumber oil therapy gave a faster healing time which was very significant compared to honey group. This healing effect is related to the ability of sea cucumber oil to have a broad-spectrum antibiotic effect that not only prevents infection, but also eradicates bacteria from wounds [9]. Sea cucumber oil is proven to contain anti-free radical components and works as an anti-inflammatory agent and a variety of bioactive ingredients, especially triterplikosida (saponins), chondroitin sulfate, glycosaminoglycans (GAG), polysaccharide sulphates, sterols (glycosides and sulphates), phenolics, serberosides, lectins, peptides, glycoproteins , glycosfingolipid and essential fatty acids so that it can overcome damage to skin tissue exposed to radiation [9]. Eradication of bacteria is very important in wound healing. Bacterial infections can inhibit wound healing. Sea cucumber oil stimulates the production of IL-2 and B cells to increase phagocytosis so that it can prevent and inhibit bacterial infections [24, 25]. However, in addition to the process, there are another active substances in sea cucumber oil, methanolic extract which has a strong antibacterial effect, even has effect of inhibiting bacterial growth Methicillin Resistant S. aureus (MRSA) and Methicillin Sensitive S. aureus (MSSA) [26].

The advantages of sea cucumber oil on bacterial eradication are not only bacteria that are sensitive to methicillin but also to bacteria that are resistant to methicillin. Staphylococcus aureus is a bacterium that often causes infections of the skin and connective tissue and also one of the bacteria that most often causes nosocomial infections, so eradication of these germs is very important for wound healing, especially in the skin and connective tissue [26]. Lysozyme has an antibacterial effect and is an important component in the innate immune system. The enzyme has muramidase activity which catalyzes the cleavage of glycoside bonds between $\mathrm{N}$-acetylmuramic acid and $\mathrm{N}$-acetylglucosamine on the bacterial wall so that it can eradicate bacteria. Lysozyme and antibacterial peptides in sea cucumber oil have a broad-spectrum antibacterial effect that includes gram-positive and gram-negative bacteria [27]. Based on structural characteristics and activities, lysozyme is divided into six types, namely chicken type (c-type), goose type (g-type), invertebrate type (i-type), phage lysozyme, bacterial lysozyme, and plant lysozyme. I-type Lysozyme is one that has been studied containing muramidase enzyme and non-enzymatic activity which has an antibacterial effect on gram-positive and gram-negative bacteria. One of the peptides contained in sea cucumber oil is the SjLys-C peptide which has an antibacterial effect through non-enzymatic reactions. The helix loop-helix (HLH) structure of the SjLys-C peptide causes an antibacterial effect on gram-positive and gram-negative bacteria [27].

About 70 percent of the protein in the sea cucumber oil body wall consists of collagen. Collagen is an important component in preparing connective tissue. Collagen is further converted into gelatin by boiling, to become a functional bioactive compound. Sea cucumber oil contains a lot of collagen, causing rapid epithelialization, increasing granulation tissue formation, and reducing edema and exudation of the wound [24]. Sea cucumber oil has an active component called glycosaminoglycan (GAG) which affects the physiological active function of the body including the process of wound healing. GAG is also called mucopolysaccharide which is a complex carbohydrate molecule that binds to proteins in physiological and pathological processes. There are two types of GAG, namely GAG sulfated and non-sulfated GAG. GAG sulfated including chondroitin sulfated, dermatan sulfate, keraf sulafate, heparan sulfate and heparin. Chondroitin sulfate and liver Sulfate is proven to have positive implications for accelerating wound healing by inducing faster wound contractions, because wound contraction is a significant role in healing wounds, especially on the skin [28]. Sea cucumber oil has high efficacy but does not contain cholesterol. Sea cucumber oil contains more than 50 types of nutrients such as vitamins B1, B2, calcium phosphate, iron, iodine, vanadium, zinc, potassium, chromium, and acid benzoid [27].

Fredalina et al, said that fatty acids are the main component of sea cucumber oil which plays a role in the process of tissue repair and wound healing. These fatty acids are myristic (C14: 0), palmitic (C16: 0), stearic (C18: 0), linoleic (C18: 2), arachidic (C20: 0), eicosapentaenoic (C20: 5, EPA) and docosahexaenoic acid (C22: 6, DHA). The benefits of arachidonic acid act as eicosanoids precursors and the main component of phospholipids on cell membranes. It is known that sea cucumber oil plays a potential role in the process of growth, and blood clotting and wound healing. This supports the use of sea cucumber oil as a traditional drug for burns and wounds in Asia for a long time. Sea cucumber oil contains branched chain fatty acids (branched chain fatty acids (BCFA)) especially eicosapentaenoic acid (EPA C20: 5), and docosahexaenoic 60 acid (DHA C22: 6) which plays 
a role in wound healing activities by inhibiting prostaglandin and antithrombotic effects [25]. Sea cucumber oil can increase wound contraction and increase histological reorganization and regeneration of tissue burns. Furthermore, sea cucumber oil dressing modulates the inflammatory response, stimulates activation and proliferation of fibroblasts, and rapidly increases tissue production of collagen fibers resulting in shorter healing times. Proinflammatory cytokine levels IL-1a, IL-1b, and IL-6, are significantly reduced in wounds sea cucumber oil treated patients compared with the control group assessed by reverse transcription-polymerase chain reaction (RT-PCR) [8].

Active metabolites from sea cucumber oil have been known to induce tissue repair and wound healing. Several studies have shown that sea cucumber oil has strong anti-inflammatory, antibacterial and antioxidant substances, which are important for accelerating the wound healing process Compounds isolated from sea cucumber oil are known to have a role as an inhibitor of serine protease which plays a major role in direct inactivation of inflammatory mediators. The increase in serine protease in wounds that do not heal has been associated with an important and necessary degradation of growth factors and fibronectin for wound healing. Meanwhile, the antioxidant activity of sea cucumber oil associated with its constituents in the form of phenolics, especially flavonoids that play a role against oxidative reactions, especially those initiated by peroxyl radicals results in a reduced risk of tissue oxidative damage [8].

Burns treated with sea cucumber oil compared to controls show evidence of healing earlier where the process of re epithelialization of proliferation and migration of keratinocytes to the center of the wound just above the newly formed granulation tissue and under the scab wound. The epidermal layer thickens and is cut off at its ends as a result of mitotic cell basal activity. Signs of the healing process are noted when there is neovascularization and develop granulation tissue which is below the wound margin in all groups. There is an increase in the number of blood vessel-like structures with prominent vasodilation and a reduced inflammatory process. However, residual necrosis marked by infiltration of inflammatory cells can still be observed. Levels of IL1a, IL-1b, and IL-6 in wounds treated with sea cucumber oil were maintained at a lower level during the healing process compared to other group experiments. The level of pro inflammatory cytokines in wounds that are not treated with sea cucumber oil is still high and generally decreases after 14 days [8].

The best known role of honey is its ability to prevent and inhibit bacterial infections, thereby helping wound healing. Initially, this role was believed to be part of the biochemical properties of honey related to the formation of peroxide through intrinsic glucose oxidase activity [18]. The nature of honey with a high level of osmolarity is caused by high sugar content to dilute products from microbes and to stop the growth of all microbial species. Topical use of honey has been reported to accelerate wound healing. Honey can provide healing in wounds that do not respond to conventional therapy by using antibiotics and antiseptics, including wounds infected with bacteria that are resistant to antibiotics such as Methicillin Resistant Staphylococcus aureus [20]. Honey contains the enzyme Glucose oxidase, when diluted honey produces hydrogen peroxide with concentration the low one which can be antiseptic and antimicrobial, because this productivity continues, it functions as an antibacterial agent even though the concentration of honey $1 \mathrm{mmol} / \mathrm{L}$ needed to get the effectiveness of hydrogen peroxide as an antibacterial is about 1000 times lower than the usual 3\% hydrogen peroxide. Although osmotic inhibition of bacterial growth is lost when honey is diluted with exudate fluid from the wound, antibacterial activity remains important [20].

Honey creates a humid environment by reducing lymph fluid from wound tissue through high osmotic work. With honey the debridement effect was obtained because of the activation of the protease enzyme by releasing hydrogen peroxide [21]. Honey is said to have no side effects on body tissues. Therefore, it is said to be safe for use in wounds, both surgical wounds, infection wounds and inserted into cavities or sinuses to eliminate infection, and is used in cases of fractures with infected wounds $[29,30]$. The concentration of honey is $0.1 \%$ has been found to stimulate proliferation of lymphocytes and $\mathrm{T}$ lymphocytes from peripheral blood and activate phagocytes from blood and also honey at a concentration of $1 \%$ has been reported to stimulate monocytes in cell cultures to release cytokines TNF-1, IL-1 and IL-6. Giving topical substances to wounds containing hydrogen peroxide can increase the formation of new capillaries. With a low concentration of hydrogen peroxide it can be used to stimulate wound healing $[20,30]$. Beretta et al conducted a study that showed radical activity scavenging in honey. This study supports previous research which stated that honey can reduce the release of reactive oxygen intermediates [19, 20, 30].
Honey can regulate the production of TNF- $\alpha$, IL-1 $\beta$, IL-6, and prostaglandin E2 as macrophage precursor cells. Macrophages have many roles in wound healing, from cleaning debris, and the formation of new blood vessels [19, 20, 29].

The anti-inflammatory properties of honey can reduce inflammation and accelerate wound healing by penetrating deep into the skin tissue [19, 20, 29]. In administration of honey can increase mediator production including cytokines TNF- $\alpha$, IL- $1 \beta$ and TGF- $\beta$ so that there is degradation of type IV collagen in the basement membrane which causes faster healing of wounds [31]. Honey can improve tissue granulation and epithelialization in the proliferation phase, and reduce the time needed for wound healing. The increase in the remodeling phase caused increased regulation of metalloproteinase-9 (MMP-9) and transforming growth factor- $\beta$ (TGF- $\beta$ ) in fibroblast-mediated epidermal keratinocytes [31]. Sea cucumber oil and honey have different mechanisms in the process of wound healing. Both can accelerate wound healing. Sea cucumber oil has more compounds that honey does not have which can accelerate wound growth such as triterplikosida (saponin), glycosaminoglycans (GAG) which include condritin sulfate and heparan sulfate, polysaccharide sulfate, sterols (glycosides and sulfates), phenolics, serberosides, lectins, peptides, glycoproteins, glycosfingolipids, essential fatty acids, serine proteases, arachidonic acid, and flavonoids, and contain nutrients such as vitamins B1, B2, calcium phosphate, iron, iodine, vanadium, zinc, potassium, chromium, and benzoid acid. Whereas honey has TNF- $\alpha$, IL-1 $\beta$, TGF- $\beta$ and MMP9 cytokines on keratinocytes which cause degradation of type IV collagen which accelerates wound healing.

Honey also has an increase in TNF- $\alpha$, IL-1 $\beta$, IL-6, and prostaglandin E2 which has the effect of accelerating wound healing through activation of macrophages that help clear debris, and the formation of new blood vessels. Sea cucumber oil also has antibacterial effects such as IL-2 and B cells to increase bacterial phagocytosis, methanolic extract which has antibacterial properties against MRSA and MSSA, and i-type Lysozyme which has a broad-spectrum antibacterial effect. Antibacterial effects are very important to prevent infections that can slow wound healing. While honey has broad spectrum antibacterial properties through the enzyme Glucose oxidase which produces hydrogen peroxide and honey properties which have high osmolarity.

The antibacterial effect in sea cucumber oil may be stronger than in honey because it has an antibacterial effect on MRSA and MSSA that honey does not have. Collagen contained in the sea cucumber oil can accelerate epithelialization, increase the formation of granulation tissue, and reduce edema and exudation of the wound so as to accelerate wound contraction which is an important process in wound closure. This process occurs in the remodeling phase. While honey can improve tissue granulation and epithelialization during the proliferation and remodeling phase, and honey has an anti-inflammatory effect by penetrating under the skin. However, the remodeling phase on wound healing that is affected by sea cucumber oil has a better role than honey even though honey can affect the inflammatory phase, proliferation and remodeling phases.

Table 5. Comparison sea cucumber oil and honey on wound healing

\begin{tabular}{|c|c|c|}
\hline & Honey & Sea cucumber oil \\
\hline Antibacterial & $\begin{array}{l}\text { 1. Glucose activity of intrinsic } \\
\text { oxidation forming peroxide [18] } \\
\text { 2. High osmolarity capable of dilution } \\
\text { of microbial products }[20,21] \\
\text { 3. Methylglyoxal (MGO) is able to } \\
\text { inhibit the formation of } \\
\text { biofilms }[18,19,20]\end{array}$ & $\begin{array}{l}\text { 1. Methanolic extract has an } \\
\text { antibacterial effect on MRSA and } \\
\text { MSSA[10,26] } \\
\text { 2. Lysozime and peptides (SjLys-C) } \\
\text { have antibacterials against Gram- } \\
\text { positive and Gram-negative [27] }\end{array}$ \\
\hline $\begin{array}{l}\text { Immunological } \\
\text { modulator }\end{array}$ & $\begin{array}{l}\text { 1. Regulate the production of TNF- } \alpha \text {, } \\
\text { IL-1 } \beta, \text { IL- } 6 \text {, and prostaglandin E2 } \\
\text { (macrophage precursors) }[19,20,29] \\
\text { 2. Improve regulation } \\
\text { Metaloproteinase- } 9 \text { (MMP-9) and } \\
\text { transforming growth factor- } \beta \text { (TGF- } \\
\beta \text { ) in epidermis keratinocytes } \\
\text { mediated by Fibroblast.[31] }\end{array}$ & $\begin{array}{l}\text { 1. Glycine stimulates the production } \\
\text { of IL-2 and B cells to increase } \\
\text { phagocytosis[24] } \\
\text { 2. Glycine and glutamic acid play a } \\
\text { role in activation and } \\
\text { proliferation Natural Killer (NK) } \\
\text { cell[24] } \\
\text { 3. Arginine has play a role in the } \\
\text { activation and proliferation of T- } \\
\text { cells[24] }\end{array}$ \\
\hline $\begin{array}{l}\text { Physiological } \\
\text { mediators }\end{array}$ & $\begin{array}{l}\text { 1. Anti-inflammatory }[19,20,29] \\
\text { 2. Enhances granulation and } \\
\text { epithelialization in the proliferation } \\
\text { phase }[19,20,21,31]\end{array}$ & $\begin{array}{l}\text { 1. Anti-Oxidant and Anti- } \\
\text { inflammatory[9] } \\
\text { 2. High collagen content can } \\
\text { accelerate epithelialization, } \\
\text { increase of granulation tissue } \\
\text { formation, reduce edema and } \\
\text { exudation of Wounds In the } \\
\text { remodeling phase [24] } \\
\text { 3. Glycosaminoglycan (GAG) } \\
\text { speeds up wound healing by } \\
\text { inducing faster wound } \\
\text { contraction [28] }\end{array}$ \\
\hline
\end{tabular}




\section{CONCLUSION}

Improvement of skin conditions in the administration of sea cucumber oil is better and faster than the administration of honey in patients with nasopharyngeal carcinoma after radiotherapy. It should be considered that sea cucumber oil can be used as a standard therapy for every patient with nasopharyngeal carcinoma who suffers from skin damage after radiotherapy.

\section{REFERENCE}

[1] Adham M, Kurniawan AN, Muhtadi AI, et al. Nasopharyngeal carcinoma in Indonesia: epidemiology, incidence, signs, and symptoms at presentation. Chinese journal of cancer. 2012;31(4):185.

[2] Madani D, Akbar N, Permana A. Prevalence of nasopharyngeal carcinoma in the Department of ENT-HNS Padjadjaran University/RSUP Dr. Hasan Sadikin Bandung period. 2010;2014:1-14.

[3] Wei W, Chua D. Nasopharyngal cancer. in Bailey BJ, Healey GB, Johnson JT, et.al, editor. Head and Neck Surgery Otolaryngology. 4th ed. Lippincott Williams \& Wilkins, Philadelphia. 2006;1875;97.

[4] Kumar S, Juresic E, Barton M, et.al. Management of skin toxicity during radiation therapy: a review of the evidence. Journal of Medical Imaging and Radiation Oncology. 2010;54(3):264-79.

[5] Team PRRR. Managing Radiotherapy Induced Skin Reactions, A Toolkit for Healthcare Professionals. Leeds Teaching Hospitals NHS Trust Leeds; 2011.

[6] Pitoyo. Treatment Effectiveness Second-degree burns between using honey and olive oil on the back of the rat wistar strain. Surakarta: Muhammadiyah University; 2013.

[7] Zancan P, Mourão PA. Venous and arterial thrombosis in rat models: dissociation of the antithrombotic effects of glycosaminoglycans. Blood Coagulation \& Fibrinolysis. 2004;15(1):45-54

[8] Zohdi RM, Zakaria ZAB, Yusof N, et.al. Sea cucumber (Stichopus hermanii) based hydrogel to treat burn wounds in rats. Journal of Biomedical Materials Research Part B: Applied Biomaterials. 2011;98(1):30-7.

[9] Subramaniam BS, Amuthan A, D'Almeida PM, et.al. Efficacy of gamat extract in wound healing in albino wistar rats. Int J Pharm Sci Rev Res. 2013;20(1):142-5.

[10] Mariana, NS, Nik KANI, Neela VK, et.al. In vivo evaluation on Malaysian coastal isolates of Gracilaria changii and Stichopus badionotus through heat-burn methicillin-resistant Staphylococcus aureus (MRSA) infection animal model. Afr. J. Microbiol. Res. 2011, 5 , 1379-1382.

[11] Hawa I Jr, Zulaikah M, Jamaludin M, et al. The potential of the coelomic fluid in sea cucumber as an antioxidant. Malays. J. Nutr. 1999, 5, 55-59.

[12] Harper CR, Jacobson TA. Usefulness of omega-3 fatty acids and the prevention of coronary heart disease. The American Journal of Cardiology. 2005;96(11):1521-9.

[13] Kariya Y, Mulloy B, Imai K, et al. Isolation and partial characterization of fucan sulfates from the body wall of sea cucumber Stichopus japonicus and their ability to inhibit osteoclastogenesis. Carbohydrate Research. 2004;339(7):1339-46.

[14] Liu HH, Ko W-C, Hu ML. Hypolipidemic effect of glycosaminoglycans from the sea cucumber Metriatyla scabra in rats fed a cholesterolsupplemented diet. Journal of Agricultural and Food Chemistry. 2002;50(12):3602-6.

[15] Yang P, Collin P, Madden T, et al. Inhibition of proliferation of PC3 cells by the branched - chain fatty acid, 12 - methyltetradecanoic acid, is associated with inhibition of 5 -lipoxygenase. The Prostate. 2003;55(4):281-91.

[16] Zou ZR, Yi YH, Wu HM, et.al. Intercedensides A- C, three new cytotoxic triterpene glycosides from the sea cucumber Mensamaria intercedens Lampert. Journal of Natural Products. 2003;66(8):1055-60.

[17] Robson V. Using honey to treat skin damaged by radiotherapy. Wounds UK. 2009;5(1):51-7.

[18] Henriques A, Jackson S, Cooper R, et.al. Free radical production and quenching in honeys with wound healing potential. Journal of Antimicrobial Chemotherapy. 2006;58(4):773-7.

[19] Sumardhika D. Effect of topical honey on the rate of speed of repair of damage to neck skin after radiotherapy in nasopharyngeal carcinoma patient. Bandung: Padjadjaran University; 2013.

[20] Lee DS, Sinno S, Khachemoune A. Honey and wound healing. American Journal of Clinical Dermatology. 2011;12(3):181-90.
[21] Simon A, Traynor K, Santos K, et.al. Medical honey for wound carestill the 'latest resort'? Evidence-Based Complementary and Alternative Medicine. 2009;6(2):165-73.

[22] Cao S-M, Simons MJ, Qian C-N. The prevalence and prevention of nasopharyngeal carcinoma in China. Chinese Journal of Cancer. 2011;30(2):114.

[23] Indonesian Ministry of Health. Practical guidelines for monitoring adult nutritional Status. Available from http://gizi.depkes.go.id. 2012.

[24] Saito M, Kunisaki N, Urano N, et.al. Collagen as the major edible component of sea cucumber (Stichopus japonicus). Journal of Food Science. 2002;67(4):1319-22.

[25] Fredalina B, Ridzwan B, Abidin AZ, et al. Fatty acid compositions in local sea cucumber. General Pharmacology: The Vascular System. 1999;33(4):337-40.

[26] Mariana N, Norfarrah M, Nik K, et.al. Evaluating the antibacterial activity and in vivo assay of methanolic extract of Stichopus badionotus. Int J Pharmacol. 2009;5(3):228-31.

[27] Cong L, Liang W, Wu Y, et al. High-level soluble expression of the functional peptide derived from the C-terminal domain of the sea cucumber lysozyme and analysis of its antimicrobial activity. Electronic Journal of Biotechnology. 2014;17(6):280-6.

[28] Masre SF, Yip GW, Sirajudeen KN, et.al. Wound healing potential of total sulfated glycosaminoglycan (GAG) from malaysian sea cucumber, Stichopus vastus coelomic fluid. Research Journal of Medical Sciences. 2015;9(3):67-72.

[29] Tonks AJ, Cooper R, Jones K, et.al. Honey stimulates inflammatory cytokine production from monocytes. Cytokine. 2003;21(5):242-7.

[30] Beretta G, Orioli M, Facino RM. Antioxidant and radical scavenging activity of honey in endothelial cell cultures (EA. hy926). Planta Medica. 2007;73(11):1182-9.

[31] Majtan J, Kumar P, Majtan T, et.al. Effect of honey and its major royal jelly protein 1 on cytokine and MMP - 9 mRNA transcripts in human keratinocytes. Experimental Dermatology. 2010;19(8):e73-e9. 